\title{
Microstructure and properties of PET/EPDM, EPDM-g- MA/organoclay ternary hybrid nanocomposites: effect of blending sequence
}

\author{
Morad Ali Khatibi, ${ }^{1}$ Ahmad Arefazar, ${ }^{1 *}$ Masoud Esfandeh ${ }^{2}$ \\ ${ }^{1 *}$ Polymer Engineering Department, Amir Kabir University of Technology, Tehran, \\ Iran; fax: +98-21-66468243; e-mail: arefazar@iut.ac.ir \\ 2 Composites Department, Iran Polymer and Petrochemical Institute, P. O. Box \\ 14965/115, Tehran, Iran.
}

(Received: 31 August, 2008; published: 27 December, 2008)

\begin{abstract}
Poly(ethylene terphthalate) (PET)/organomontmorilonite (OMMT)/maleic anhydride ethylene-propylene-diene rubber (EPDM-g-MA) nanocomposites were prepared via melt blending of the ingredients in a Haake Rheocord mixer. To make the hybrid composites, four different blending routes were examined: 1) preparing EPDM/EPDM-g-MA (EPMA)/organoclay nanocomposite and then blending it with PET, $\left.\left(S_{1}\right), 2\right)$ dispersion of organoclay in PET and then blending it with EPMA, $\left(S_{2}\right)$, 3) blending PET with EPMA and then mixing it with organoclay, $\left.\left(S_{3}\right), 4\right)$ blending PET, EPMA and organoclay in a single process, $\left(\mathrm{S}_{4}\right)$. The microstructure of the $\mathrm{PET} /(\mathrm{EPMA}) /$ organoclay ternary hybrids were characterized by X-ray diffraction (XRD) and Transmission Electron Microscopy (TEM). The result showed that the blending sequence greatly affects the dispersion of organoclay in the polymer matrix as well as the microstructure of the blends. Mechanical behavior of the blends including tensile and impact properties were also studied. Results revealed that PET/ (EPMA)/organoclay nanocomposites made by mixing sequence, $\mathrm{S}_{1}$, has the maximum tensile and impact strength among the others. This was attributed to its fine "Sea-Island" morphology and good dispersion of the organoclay in the continuous PET matrix.

Keywords: PET, Organoclay, Ternary Nanocomposites, Morphology
\end{abstract}

\section{Introduction}

Nanocomposites of polymer layered silicates (PLS) have attracted the attention of researchers due to their outstanding mechanical, thermal and barrier properties. These nanocomposites can be prepared by various methods: solution intercalation, in-situ intercalative polymerization and polymer melt intercalation. Among these, the melt intercalation is of much interest because of its versatility, compatibility with current polymer processing techniques and its environmentally benign character due to the absence of solvent. Many polymers with varying degree of polarity and chain rigidity have been studied as the base polymers to prepare PLS nanocomposites via the melt process. Nylon [1-2], polystyrene [3-5], polypropylene [6-9], PET [10-15] and poly(butylene therephthalate), PBT[17] are examples of such systems. The presence of nano particles in these systems led to an improvement in some properties (e.g. tensile strength and modulus, heat distortion temperature) in comparison to their parent matrix polymers [16-19].

PET is an important engineering thermoplastic with many useful properties such as high degree and rate of crystallization, good chemical resistance, thermal stability 
and excellent flow properties. However, it suffers from notch sensitivity and low resistance to crack propagation and growth. Many attempts have been made to improve impact properties of PET by blending it with rubbery polymers such as ethylene vinyl acetate, EVA [20-21], ABS[22-23], SBR[24], EPDM [16,19] and etc. Although this improves the impact resistance to some extent, but it also adversely affects other properties such as tensile strength, modulus and heat distortion temperature. Some researchers have studied melt crystallization kinetics of PET/organoclay nanocomposites [25-28]. Attempts have been made to improve dimensional thermal stability of PET fibers by preparing PET/OMMT nanocomposites and other properties of nanocomposites [15]. The properties of ternary nanocomposite systems having two polymer phases can be interesting and is controlled by various parameters such as the dispersion and extent of intercalation of organoclay in these phases, mixing sequence of the components, etc [30-32] and therefore, a range of properties is expected for ternary systems. Little literature have been reported on such systems. In one case, effect of blending sequence on microstructure and properties of PBT/EVA-g-MA/organoclay ternary nanocomposites was studied by Xiucuo et al [17]. Here, maximum impact resistance was obtained for the system in which organoclay was first melt blended with PBT and then EVA-g-MA was added. A Sea-Island microstructure was observed for this system. There are no reports on PET/(EPMA)/Organoclay ternary nanocomposites.

The objective of this research is to study the effect of blending sequence on microstructure and properties of PET/EPDM, EPDM-g-MA/organoclay nanocomposites. To increase the compatibility of the blend components, a constant amount of EPDM-g-MA was used in all formulations. Ternary nanocomposites, PET/ EPMA /organoclay were prepared through melt intercalation method. To prepare the ternary nanocomposites, four different blending routes were followed: 1) preparing EPMA/Organoclay nanocomposites and then blending it with PET, $\left.\left(S_{1}\right), 2\right)$ dispersion of organoclay in PET and then blending it with EPMA, $\left.\left(S_{2}\right), 3\right)$ blending PET with EPMA and then mixing it with organoclay, $\left.\left(S_{3}\right), 4\right)$ blending PET, EPMA and organoclay in a single process, $\left(\mathrm{S}_{4}\right)$.

\section{Results and Discussion}

In Fig.1, SEM micrographs of the hybrids prepared by various mixing sequence are shown. As it is evident, the blend prepared by the procedure $S_{1}$ has uniform morphology and shows a good interfacial adhesion between the phases (Fig. 1a). For the blends prepared by other mixing sequences i.e. $S_{2}, S_{3}$ and $S_{4}$ the morphology is quite different and seems the interfacial adhesion is not satisfactory (Fig. 1b, 1c and 1d). These are further evident in Fig. 2 where the micrographs are shown in higher magnification. Here, the uniformity and improved interfacial adhesion for $S_{1}$ blend can be observed (Fig. 2a). With the other series, $S_{2}$ and $S_{3}$, these properties become poor (Fig. $2 b$ and $2 \mathrm{c}$ ) and in $\mathrm{S}_{4}$ blend, in which the components are mixed in a single process, non-uniformity in the blend morphology and poor adhesion of the phases shown in form of separation, is quite clear (Fig. 2d). EPDM phase, seen as separated white areas, is observed in $S_{4}$ and to less extent for $S_{3}$ and $S_{2}$ blends but not for $S_{1}$ blend. These suggest that $S_{1}$ blend should have superior properties than its counterparts.

In Fig. 3 XRD patterns of PET/EPMA/organoclay blends prepared by various mixing sequences are compared with Cloisite ${ }^{\circledR} 15 \mathrm{~A}$. 

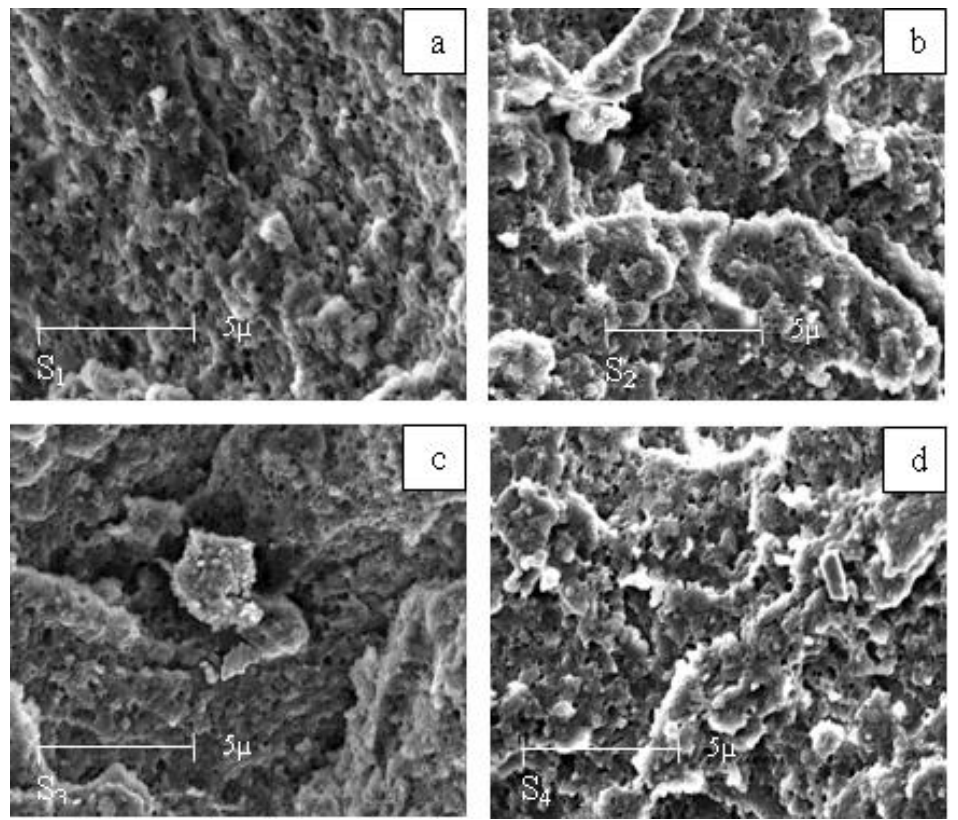

Fig. 1. SEM micrographs of the blends prepared by various mixing sequences; a) $S_{1}$, b) $S_{2}$, c) $S_{3}$ and d) $S_{4}$.
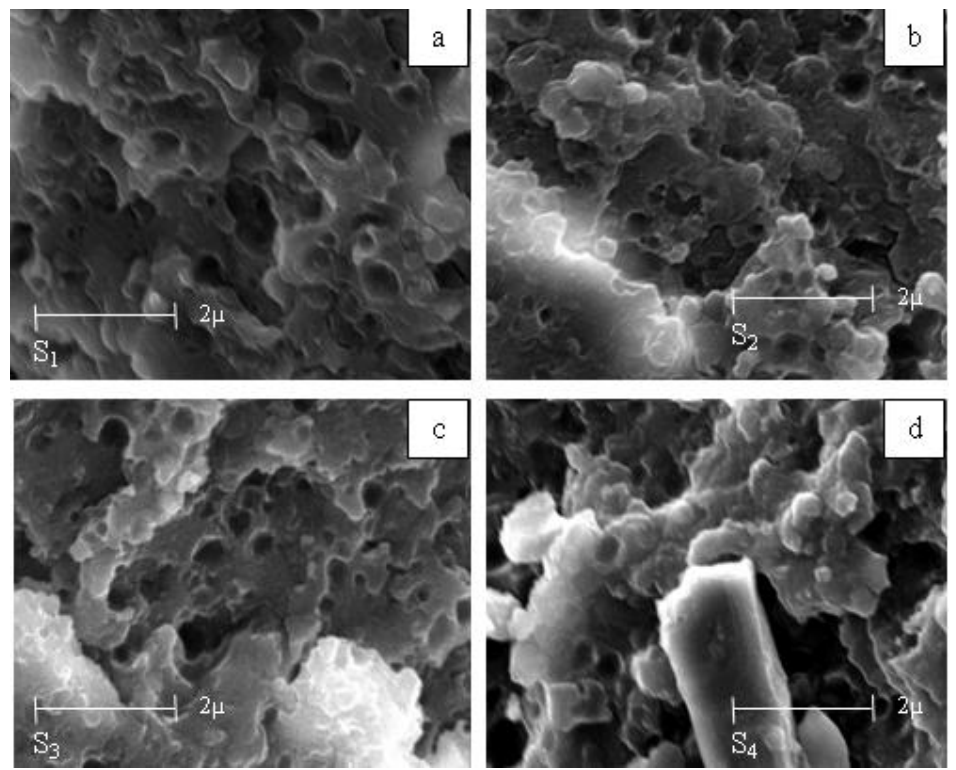

Fig. 2. SEM micrographs of the blends prepared by various mixing sequences; a) $S_{1}$, b) $S_{2}$, c) $S_{3}$ and d) $S_{4}$ (Higher magnification).

As it is shown, d-spacing in Cloisite ${ }^{\circledR} 15 A$ is $3.03 \mathrm{~nm}\left(2 \theta=2.85^{\circ}\right)$, however, this is changed for the hybrid blends and an increase in d-spacing of the layered silicate is observed. This increase is attributed to the penetration of the polymer chains between the interlayer spaces and suggests the intercalated nanostructure of PET/EPMA/organoclay hybrid nanocomposite. The basal spacing in the blends prepared by procedure $S_{1}$ is $3.50 \mathrm{~nm}\left(2 \theta=2.47^{\circ}\right)$ while this is $3.44,3.39$ and $3.34 \mathrm{~nm}$ $\left(2 \theta=2.51^{\circ}, 2.55^{\circ}\right.$ and $\left.2.59^{\circ}\right)$ for those prepared by $S_{2}, S_{3}$ and $S_{4}$ procedures, respectively. This indicates that the extent of intercalation in $S_{1}$ hybrid is higher than that of $S_{2}, S_{3}$ and $S_{4}$ hybrids and that a partial exfoliation may also have happened. 


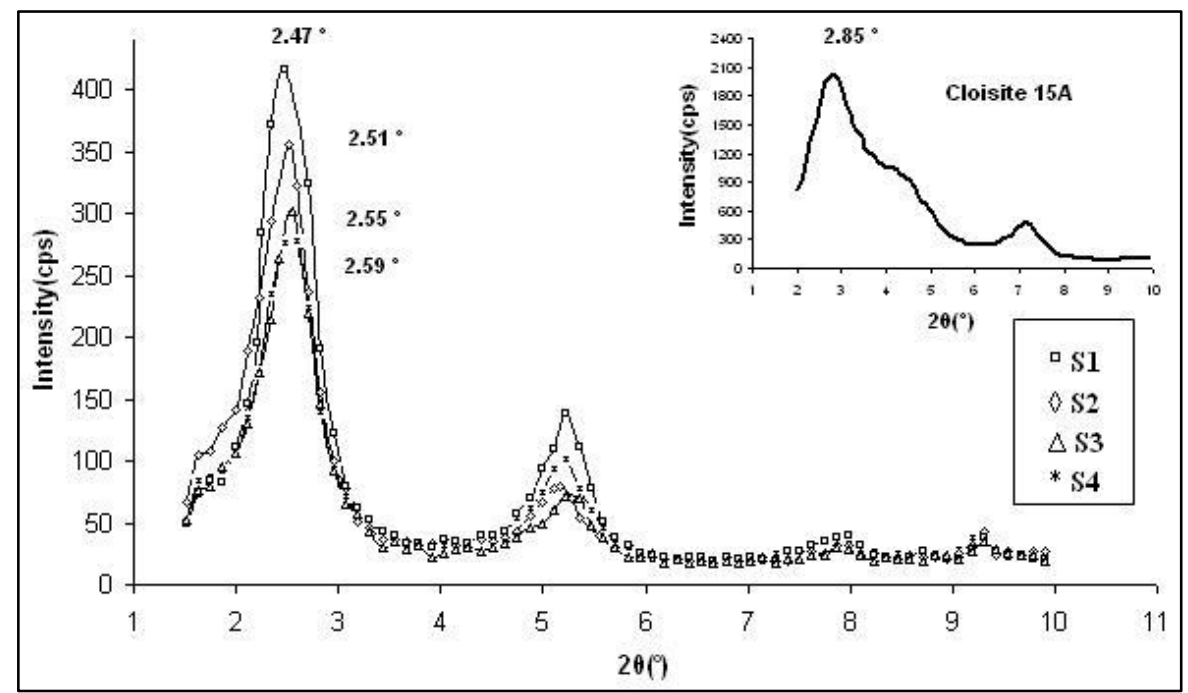

Fig. 3. XRD patterns for Cloisite ${ }^{\circledR} 15 A$ and PET/ EPMA/Organoclay hybrid blends prepared by various mixing sequences; $S_{1}, S_{2}, S_{3}$ and $S_{4}$.

In order to study the compatibility of Cloisite ${ }^{\circledR} 15 \mathrm{~A}$ with both PET and EPDM, the naocomposites PET/ Cloisite ${ }^{\circledR} 15 \mathrm{~A}$ (3\% wt.) and EPMA/ Cloisite ${ }^{\circledR}$ 15A, 50:50:3(wt\%) were prepared. In Fig. 4 XRD patterns of these nanocomposites are shown. For EPMA/ Cloisite ${ }^{\circledR} 15 \mathrm{~A}$ system a peak is observed at $2.24^{\circ}$ which confirms the intercalation and exfoliation of Cloisite ${ }^{\circledR} 15 A$ in EPDM system. This can be attributed to a good compatibility of the modifying agent in Cloisite ${ }^{\circledR} 15 A$ and EPMA. In XRD pattern of the PET/ Cloisite ${ }^{\circledR} 15 \mathrm{~A}$ system (Fig. 4), a peak at $2.59^{\circ}$ is appeared which shows an increase in d-spacing of Cloisite ${ }^{\circledR} 15 \mathrm{~A}$ and thus the intercalation of the nano particles in PET matrix has happened. From these results one may conclude that EPMA has a better compatibility with Cloisite ${ }^{\circledR} 15 \mathrm{~A}$ than that of PET. Thus, in preparing the ternary nanocomposites of PET/EPMA/ Cloisite ${ }^{\circledR} 15 \mathrm{~A}$, the preferred mixing sequence is to blend EPDM with Cloisite ${ }^{\circledR} 15 A$ and then with PET, i.e. $S_{1}$ mixing sequence. The XRD results for the individual systems (Fig. 4) confirm the results obtained for hybrid systems (Fig. 3). As expected, when PET is added to EPMA/ Cloisite ${ }^{\circledR} 15 A\left(S_{1}\right.$ method) there will be a competition for the dispersion of Cloisite $^{\circledR} 15 \mathrm{~A}$ between the phases. However, it mainly tends to remain in EPMA phase (where it has already been dispersed) and only a portion of it will remain in PET phase, upon compounding. Having $2 \theta$ values for the individual systems $\left(2.24^{\circ}\right.$ and $\left.2.59^{\circ}\right)$ in mind, it is reasonable to see an increase in $2 \theta\left(2.47^{\circ}\right)$ for the hybrid system $S_{1}$. With the simultaneous presence of PET and EPMA phase ( $S_{4}$ method) the extent of intercalation and exfoliation (comparing with $S_{1}$ method) is reduced (and hence $2 \theta$ is increased to $2.59^{\circ}$ ) perhaps due to difficulty for the dispersion of Cloisite ${ }^{\circledR}$ $15 \mathrm{~A}$ between the two phases which have different melt viscosities and are not being efficiently mixed, yet. Studies of the $S_{4}$ hybrid also show non-uniformity in the structure and poor adhesion between the phases (see Figs.1d and 2d). Premixing of the two matrices (PET and EPMA) and then blending them with Cloisite ${ }^{\circledR} 15 \mathrm{~A}\left(\mathrm{~S}_{3}\right.$ method) improves the situation to some extent $\left(2 \theta=2.55^{\circ}\right)$. This may be further improved by using $S_{2}$ method in which Cloisite ${ }^{\circledR} 15 \mathrm{~A}$ is at first dispersed in PET and then blended with EPMA. Here, it is believed that Cloisite ${ }^{\circledR} 15 A$ tends to migrate from PET to EPMA phase and in doing so better intercalation and exfoliation is achieved 
as compared to PET/ Cloisite ${ }^{\circledR} 15 \mathrm{~A}$ nanocomposite. This is reflected in $2 \theta$ values for these systems which are $2.51^{\circ}$ and $2.59^{\circ}$, respectively.

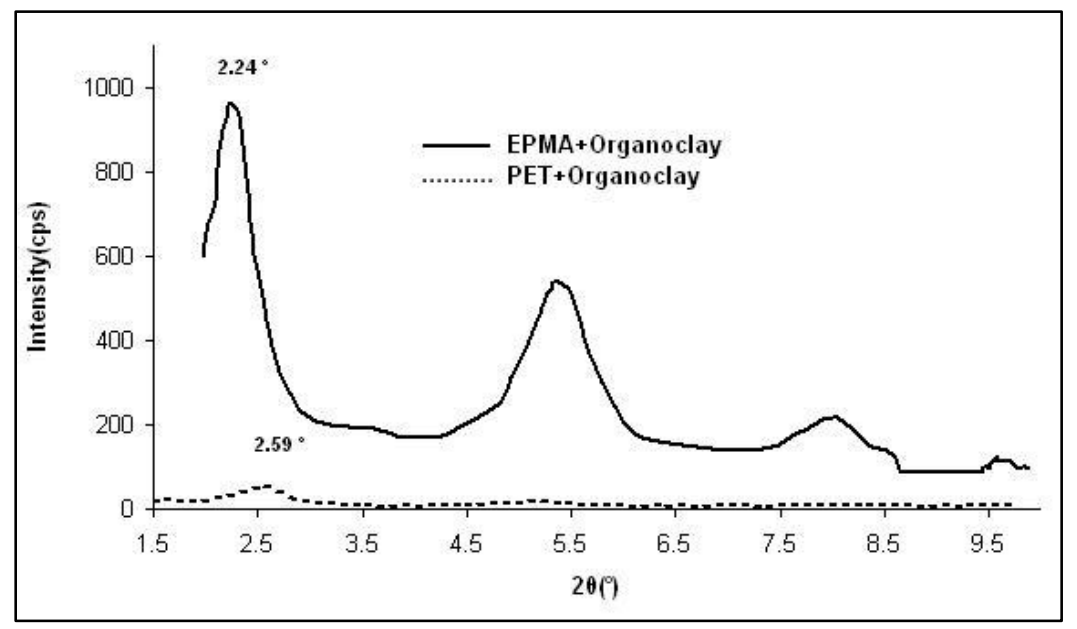

Fig. 4. XRD patterns of EPMA/ Cloisite ${ }^{\circledR} 15 A$ (3\% wt.), and PET/ Cloisite ${ }^{\circledR} 15 A$ (3\% wt.) nanocomposites.

$\mathrm{XRD}$ and TEM have been regarded as complementary in characterizing the microstructure of nanocomposites. In order to study the dispersion state of Cloisite ${ }^{\circledR}$ $15 \mathrm{~A}$ in the matrices and also the morphology of the blends in its presence, TEM micrographs were prepared.

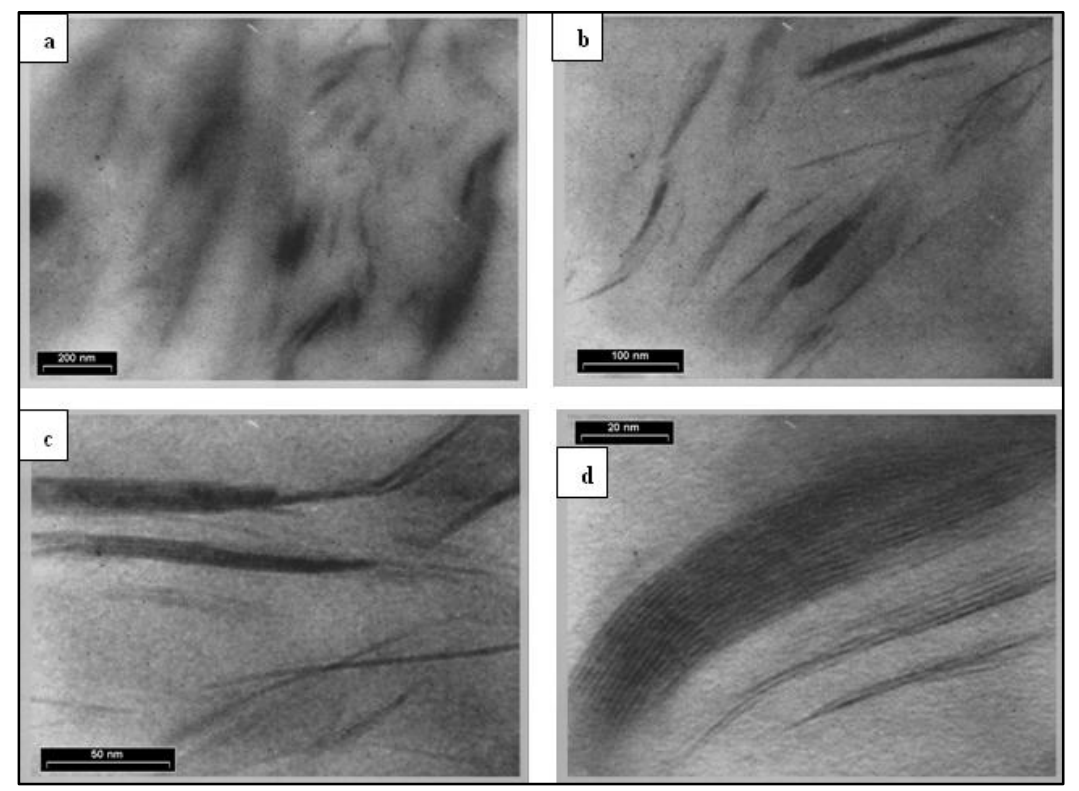

Fig. 5. TEM micrographs of $S_{1}$ ternary nanocomposite at different magnifications; a) $200 \mathrm{~nm}$, b) $100 \mathrm{~nm}$, c) $50 \mathrm{~nm}$ and d) $20 \mathrm{~nm}$.

Fig. 5 shows TEM images of $S_{1}$ ternary nanocomposite at different magnifications. Here, the intercalation and partial exfoliation of Cloisite ${ }^{\circledR} 15 \mathrm{~A}$ is clearly observed, proving the formation of the nanocomposite. These confirm the results obtained from 
XRD experiments. Also "Sea-Island" morphology can be seen for this nanocomposite (Fig. 6a) which confirms the uniform dispersion of EPMA in PET matrix, seen in SEM mirographs (Figs. 1-2).

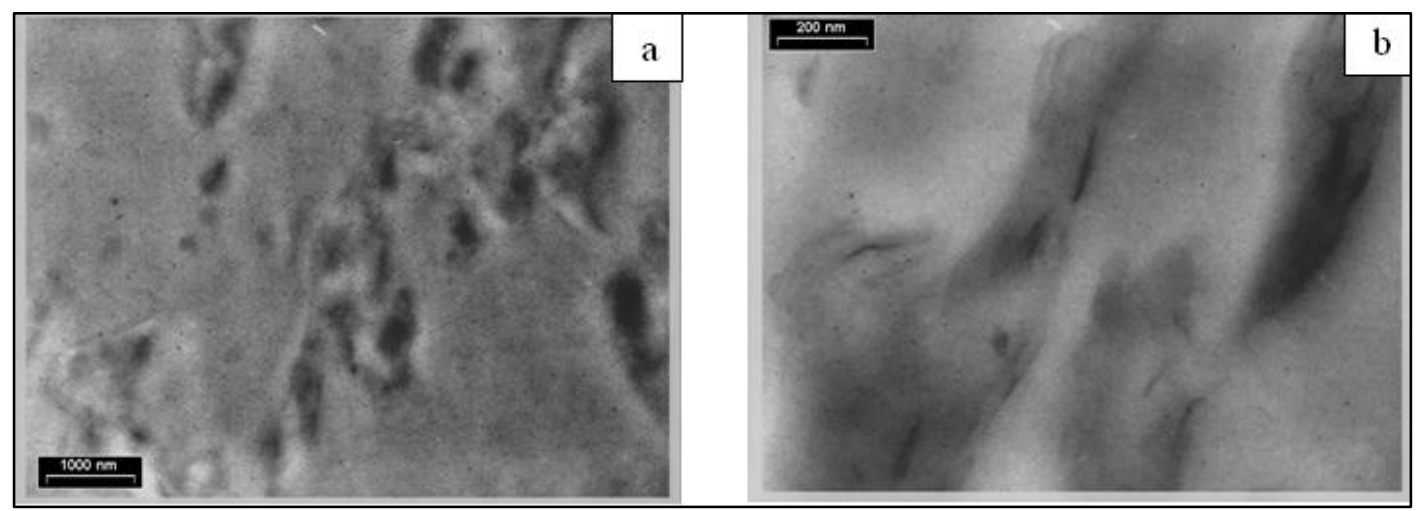

Fig. 6. TEM micrographs of ternary nanocomposite prepared by $S_{1}$ method and showing a Sea-Island morphology; a) 1000nm, b) $200 \mathrm{~nm}$.

Table 1 lists the mechanical properties of various blends. As it can be seen, the blending sequence has greatly affected the impact strength. The value of impact strength of nanocomposites lie between the impact strength of virgin PET $(26 \mathrm{~J} / \mathrm{m})$ and PET/EPDM-g-MA blends $(104.6 \mathrm{~J} / \mathrm{m})$. The $S_{1}$ series with impact strength of $99.39 \mathrm{~J} / \mathrm{m}$ shows the highest strength among the others and the rest of them varies as $S_{2}>S_{3}>S_{4}$. The exact value of impact strength of nanocomposites depends on the morphology of blends and the extent of the dispersion of nanoclay in the phases. The high impact strength of the $S_{1}$ hybrid nanocomposite can be attributed to its seaisland morphology and good dispersion of Cloisite ${ }^{\circledR} 15 \mathrm{~A}$ in the phases. Improved intercalation and exfoliation of Cloisite ${ }^{\circledR} 15 \mathrm{~A}$ in EPMA matrix for $S_{1}$ series (Fig. 5) and their good interface increase the energy dissipation as the result of impact. The difference in impact strengths of $S_{2}, S_{3}$, and $S_{4}$ series is not that magnificent but well below the $S_{1}$ series. The morphology changes as well as non-uniformity in the dispersion of Cloisite $^{\circledR} 15 \mathrm{~A}$ and EPMA in PET matrix may be accounted for low impact strength of other series. The presence of big and irregular EPMA domains in the PET matrix in $S_{3}$ and $S_{4}$ series and to some extent in $S_{2}$ series confirms this matter (see Figs 1-2). These may act as stress concentrators and hence lower the impact strength.

In Table 1 the results for tensile strength and modulus and the elongation at break for various hybrid nanocomposites are also shown. Compared with virgin PET, the yield stress and tensile strength of the hybrid nanocomposites are significantly decreased which is due to the presence of the elastomeric phase. However, the decrease for $\mathrm{S}_{1}$ series was less than other series. Almost $50 \%$ decrease in elastic modulus is also observed but the values remain in the same range for various hybrids. The elongation at break is increased for all hybrids; however, this increase for $\mathrm{S}_{1}$ series is much more evident. Here, the elongation at break is increased to $101 \%$, five times of the virgin PET $(20 \%)$. It is believed that the blending sequence and in turn the morphological structure is responsible for the results obtained for $S_{1}$ hybrid nanocomposite. 
Tab. 1. Mechanical properties of hybrid nanocomposites prepared by various blending sequences.

\begin{tabular}{cccccc}
\hline Blend & $\begin{array}{c}\text { Impact } \\
\text { Strength } \\
(\mathbf{J} / \mathbf{m})\end{array}$ & $\begin{array}{c}\text { Modulus } \\
\mathbf{( M P a )}\end{array}$ & $\begin{array}{c}\text { Elongation } \\
\text { at } \\
\text { Break(\%) }\end{array}$ & $\begin{array}{c}\text { Tensile } \\
\text { Strength(MPa) }\end{array}$ & $\begin{array}{c}\text { Yield Stress } \\
(\mathbf{M P a})\end{array}$ \\
\hline PET(Virgin) & 26 & 2529 & 20 & 32.5 & 61.9 \\
$\mathrm{~S}_{1}$ & 99.39 & 1112.7 & 101.45 & 24.5 & 32.16 \\
$\mathrm{~S}_{2}$ & 58.40 & 1204 & 35.16 & 21.2 & 28.93 \\
$\mathrm{~S}_{3}$ & 54.55 & 1196.5 & 36.31 & 22.2 & 30.06 \\
$\mathrm{~S}_{4}$ & 50.78 & 1200 & 49 & 20 & 29 \\
\hline PET/EPMA & 104.6 & 1300 & 51 & 21.5 & 32.31 \\
\hline
\end{tabular}

\section{Conclusions}

PET/EPDM,EPDM-g-MA/organoclay ternary hybrid nanocomposites were prepared through a melt blending method and the effect of blending sequence on the mechanical and morphological properties were studied.

SEM results showed that the blend prepared by the procedure $S_{1}$ has a uniform morphology and showing a good interfacial adhesion between the phases. For the blends prepared by other mixing sequences i.e. $S_{2}, S_{3}$ and $S_{4}$ the morphology is quite different and the interfacial adhesion does not look satisfactory.

XRD patterns showed an increase in d-spacing of the layered silicate as the result of the penetration of the polymer chains between the interlayer spaces. The d-spacing values for various hybrid nanocomposites suggested that the extent of intercalation in $S_{1}$ hybrid is higher than that of $S_{2}, S_{3}$ and $S_{4}$ hybrids and that a partial exfoliation may also have happened.

TEM images confirm the intercalation and partial exfoliation of Cloisite ${ }^{\circledR} 15 A$ in $S_{1}$ hybrid nanocomposites. Also, "Sea-Island" morphology was seen for this nanocomposite.

The blending sequence affects the mechanical properties. The $S_{1}$ series with impact strength of $99.39 \mathrm{~J} / \mathrm{m}$ shows the highest strength among the others and the rest of them varies as $S_{2}>S_{3}>S_{4}$.

Compared with virgin PET, the yield stress and tensile strength of the hybrid nanocomposites are significantly decreased. However, the decreases for $S_{1}$ series were less than other series. An almost $50 \%$ decrease in elastic modulus is also observed but the values remain in the same range for various hybrids. The elongation at break is increased for all hybrids; however, the increase for $S_{1}$ series is much more evident.

\section{Exprimental}

\section{Materials and Instruments}

PET (BG 350) was a bottle grade polymer kindly supplied by Tondgooyan Petrochemical Co. (Iran). EPDM elastomer, Keltan 378Z, with an ethylene content 67 wt $\%$, ethylene norbornene (ENB) content $4.8 \mathrm{wt} \%$,) and a Mooney viscosity of $53(1+4)$ at $125{ }^{\circ} \mathrm{C}$, was obtained from DSM Co., Netherlands. EPDM-g-MA elastomer (P-632) was purchased 
from Pluss Polymers Pvt. Ltd. with 0.9-1.3 wt\% MA content, India and Irganox 1010 (heat stabilizer) from Ciba Geigy Ltd. The organoclay, trade name of Cloisite ${ }^{\circledR} 15 \mathrm{~A}$, was supplied by Southern Clay Product Inc., (USA).

Impact (ASTM D 256) and tensile (ASTM D 638) tests were carried out at room temperature using a Zwick Impact tester, 5102 (Germany), and Instron 6025 (UK), respectively. Five runs were done for each measurement and the average value was reported.

XRD studies of the samples were carried out using an Expert Philips X-ray defractometer from Netherlands $(40 \mathrm{kV}, 50 \mathrm{~mA})$ at a scanning rate of $0.2 \% \mathrm{~min}$. Transmission electron microscopy (TEM) images were taken from cryogenically microtomed ultra thin sections using a Philips CM200/EDAX/FEG (40 kV, $50 \mathrm{~mA}$ ), TEM. The sections were stained by $\mathrm{RuO}_{4}$. Scanning Electron Microscopy (SEM) images were prepared from the cryogenically fractured (in liquid $\mathrm{N}_{2}$ ) surface of the samples, using a Philips XL30 (40 kV, $50 \mathrm{~mA})$.

\section{Compounding Procedure}

An internal mixer, HAAKE Rheomix(HBI System, HAAKE Buchler Product) from UK, was used for compounding. Prior to mixing, PET was fully dried in an oven at $110{ }^{\circ} \mathrm{C}$ for $8 \mathrm{~h}$. The overall mixing time in all compounds was $10 \mathrm{~min}$. Mixing temperature and rotor speed were also fixed at $260{ }^{\circ} \mathrm{C}$ and $60 \mathrm{rpm}$, respectively. Weight percent of Cloisite ${ }^{\circledR} 15 \mathrm{~A}$ in all formulations was fixed at $3 \mathrm{wt} \%$. Four mixing sequences were used to make the compounds (Table 2). The compound was then granulated using a granulator followed by drying the granules in an oven at $110^{\circ} \mathrm{C}$ for $8 \mathrm{~h}$.

The granules were then injection molded in an injection molding machine (Engle, Denmark) to make the specimens for Izod impact and tensile tests. The temperature zones were as: $180{ }^{\circ} \mathrm{C}$ (zone 1$), 220{ }^{\circ} \mathrm{C}$ (zone2), $240{ }^{\circ} \mathrm{C}$ (zone3) and $260{ }^{\circ} \mathrm{C}$ (zone4). To avoid moisture absorption, all the specimens were stored in desiccators before testing.

Tab. 2. Mixing procedures used to prepare the compounds.

\section{Mixing Preparation Method}

Procedure

$\mathrm{S}_{1} \quad$ Preparing EPMA/Organoclay nanocomposite and then blending it with PET

$\mathrm{S}_{2} \quad$ Dispersion of organoclay in PET and then blending it with EPMA

$\mathrm{S}_{3} \quad$ Blending PET with EPMA and then mixing it with organoclay

$\mathrm{S}_{4} \quad$ Blending PET, EPMA and organoclay in a single process

\section{References}

[1] Alexandre, M.; Dubois, P. Mater. Sci. Eng. 2000, 28, 1.

[2] Kim, G. M.; Lee, D. H.; Hoffmann, B.; Kressler, J.; Stöppelmann, G. Polymer, 2001, 42, 1095.

[3] Cho, J. W.; Paul, D. R. Polymer, 2001, 42, 1083.

[4] Xu, X.; Qutubuddin, S. Polymer, 2001, 42, 807.

[5] Chen, G. M.; Liu, S. H.; Zhang, S. F.; Qi, N. Macromol. Rapid. Comm. 2001, 21(11), 746.

[6] Vaia, R. A.; Jandt, K. D.; Giannelis, E. P. Chem. Mat. 1996, 8,2628. 
[7] Reichert, P.; Nib, H.; Klinke, S.; Brandsch, R.; Thomann, R.; Mulhaupt, R. Macromol. Mater. Eng. 2000, 275(2), 8.

[8] Galgali, G.; Rames, C.; Lele, A. Macromolecules, 2001, 34, 852.

[9] Kawasumi, M.; Hasegawa, N.; Kato, M.; Usuki, A.; Okada, A. Macromolecules, 1997, 30, 6333.

[10] Usuki, A.; Kato, M.; Okada, A.; Kurauchi, T. J. Appl. Polym. Sci. 1997, 63, 137.

[11] Park, J.-G.; Kim, D. -H.; Suh, K.-D. J. Appl. Polym. Sci. 2000, Vol. 78, 2227.

[12] Loyens, W.; Groeninckx, G. Macromol. Chem. Phys. 2002, 203, 1702-1714.

[13] Loyens, W.; Groeninckx, G. Polymer, 2002, 43, 21, 5679-5691.

2002, 203, 1702-1714.

[14] Liu, W.; Tian, X.; Cui, P.; Li, Y.; Zheng, K.; Yang Y. J. Appl. Polym. Sci. 2004, Vol. 91, 1229-1232.

[15] Ou, C. F.; Ho, M. T.; Lin, J. R. J. Appl. Polym. Sci. 2004, Vol. 91, 140-145.

[16] Gatos, K. G.; Thomann, R.; Karger-Kocsis,J. Z. Polym. Int. 2004, 53,1191-1197.

[17] Li, X.; Park, W.-M.; Lee, J.-O.; Ha, C.-S. Polym. Eng. Sci. 2002, Vol. 42, No. 11.

[18] Costache, M. C.; Heidecker, M. J.; Manias, E.; Wilkie, C. A. Polym. Adv. Technol. 2006, 17, 764-771.

[19] Davis, R. D.; Gilman J. W.; VanderHart, D. L. Polym. Degrad. Stabil. 2003, 79, $111-121$.

[20] Chen, W.; Xu, Q.; Yuan, R. Z. Mater. Sci. Eng. 2000, B77,15.

[21] Li, X. C.; Kang, T. K.; Cho, W. J.; Lee, J. K.; Ha, C. S. Macroml. Rapid Comm. 2001, 22, 1310.

[22] Lebaron, P. C.; Wang, Z.; Pinnavaia, T. J. J. Appl. Polym. Sci. 1999, 15, 11.

[23] Zanetti, M.; Lomakin, S.; Camino, G. Macromol. Mater. Eng. 2000, 279,1.

[24] Arefazar, A.; Moeini Jazani, O. J. Appl. Polym. Sci. 2006,Vol. 102, Issue 2, $1615-$ 1623.

[25] Park, J.-G.; Kim, D.-H.; Suh, K.-D. J. Appl. Polym. Sci. 2000, 78, 2227-2233.

[26] Wan, T.; Chen L.; Chua Y. C.; Lu, X. J. Appl. Polym. Sci. 2004,94, 1381-1388.

[27] Ignacio, J.; Ardanuy, M.; Miralles L.; Ortiz S.; Maspoch M.; Sanchez-Soto, M.; Santana, O. Macromol. Symp. 2005, 221, 63-67.

[28] Xiao, W.; Yu, H.; Han, K.; Yu, M. J. Appl. Polym. Sci. 2005, 96,2247-2252.

[29] Li, Z.-M.; Yang, W.; Huang, R.; Fang, X.-P.; Yang, M.-B. Macromol. Mater. Eng. 2004 289, 426-433.

[30] Yoon, K. H.; Polk, M. B.; Park, J. H.; Min, B. G.; Schiraldi, D. A. Polym. Int. 2005, $54,47-53$

[31] Chang, Y.-W.; Yang, Y.; Ryu, S.; Nah, C. Poly. Int. 2002, 51, 319-324.

[32] Acharya, H; Pramanik, M.; Srivastava, S. K.; Bhowmick, A. K. J. Appl. Polym. Sci. 2004, 93, 2429-2436. 